\begin{abstract}
I study the role of company start-up costs for employment performance. The model is search equilibrium with a new concept for firms. Agents have an innate managerial ability and make a career choice to become either managers or workers. Managers set up firms, post jobs and match with workers. I show that in equilibrium career choice and job creation are jointly determined. Higher start-up costs reduce overall employment but increase the size of incumbent firms. I discuss some cross-country OECD evidence which supports the model's main proposition.
\end{abstract}

Keywords: Start-up costs, regulation, employment, OECD unemployment, search and matching.

This paper was produced as part of the Centre's Technology and Growth Programme.

\title{
Acknowledgements
}

This paper was written for Festschrift Conference for Ned Phelps, Columbia University.

Christopher A. Pissarides is a Professor of Economics at the London School of Economics and a Programme Head at the Centre for Economic Performance, LSE.

Published by

Centre for Economic Performance

London School of Economics and Political Science

Houghton Street

London WC2A 2AE

(C) Christopher A. Pissarides, submitted September 2001

ISBN 0753019205

Individual copy price: $£ 5$ 


\title{
Company Start-Up Costs and Employment
}

\author{
Christopher A. Pissarides
}

September 2001

Introduction $\quad 1$

1. The economy 3

2. Decentralized search equilibrium 5

2.1 Managers and workers 6

$\begin{array}{ll}2.2 \text { Expected payoffs } & 7\end{array}$

2.3 Equilibrium 9

3. The role of start-up costs 11

$\begin{array}{ll}\text { 4. Some preliminary evidence } & 14\end{array}$

$\begin{array}{ll}\text { 5. Conclusions } & 16\end{array}$

$\begin{array}{lr}\text { References } & 17\end{array}$

$\begin{array}{ll}\text { Tables } & 18\end{array}$

$\begin{array}{ll}\text { Figures } & 20\end{array}$

The Centre for Economic Performance is financed by the Economic and Social Research Council 


\title{
Company Start-Up Cost\$and Employment $\square$
}

\author{
Christopher A Pissarides
}

September 2001

This paper is a contribution to the literature that explains cross-country differences in employment or unemployment rates in terms of structural models of the economy. Edmund Phelps contributed to this literature with his important book Structural Slumps. ${ }^{1}$ My focus in this paper is on a factor

\footnotetext{
${ }^{1}$ Earlier seminal contributions include Bruno and Sachs' (1985) E conomics of Worldwide Stagflation and Layard, Nickell and Jackman's (1991) U nemployment:M acroeconomic Performance of the Labour Market. For a more recent contribution see Blanchard (1999) and Blanchard and Wolfers (2000).
} 
that has been neglected in previous studies, the regulation of new company start-ups.

With the increasing inter-dependence of the world's industrial economies, the differences in the performance of labor markets are more likely the outcome of different institutional structures than of different experiences with macroeconomic or policy shocks. Recent evidence has revealed large differences in the regulatory environment for company start-ups across countries, even within the OECD. ${ }^{2}$ The important quantifiable variables in this framework are currently policy related: the legal rules and regulations that a new entrepreneur has to comply with before starting his or her new company. But other factors, for example those related to the availability of finance and the stigma attached to bankruptcy, are also important ingredients of this institutional structure.

Company start-up costs influence overall employment patterns through the birth (and perhaps death) of new firms, so a pre-requisite for their importance is that company births should account for a nontrivial fraction of total net job creation. Although there is controversy about the precise role of small firms in the job generation process, a consensus view is emerging that over the last thirty years small firms have become more important job creators than used to be the case. This change is partly due to the shift from manufacturing to services, where there is higher concentration of small firms, but other factors may be present too. It has even been claimed that most of the gap in net job creation between Europe and the Unites States is in the small business sector (OECD, 1987). Moreover, most net job creation in the small business sector is done by new entrants, rather then by expansions of existing firms. ${ }^{3}$ Thus, the channels through which start-up costs can influence aggregate performance appears well established in the labor markets of Europe and North America.

Although I discuss some preliminary empirical work with aggregate OECD data, my primary objective in this paper is to discuss the theory underlying the connection between start-up costs and employment performance. Detailed empirical testing is postponed to future work. I will strip the model of many important elements that careful empirical study has to take into account, in order to focus on the key links between start-up costs and em-

\footnotetext{
${ }^{2}$ For preliminary results with OECD data see Fonseca et al. (2001). For a different and more comprehensive set of data, covering 75 countries, see Djankov et al. (2000).

${ }^{3}$ See the special issue of Business E conomics, July 1994, for extensive discussion of the role of small firms in the US economy.
} 
ployment. The model that I use builds on another seminal contribution of Phelps's, search equilibrium, but uses the more recent framework developed in my book (Pissarides, 2000) and the ideas about entrepreneurship used by Lucas (1978) in his "span-of-control" model.

In order to find a role for start-up costs in the determination of employment I need a precise definition of the firm and the incentives that entrepreneurs have for creating firms. I define a firm as a collection of jobs, each one occupied by a worker or vacant, and managed by an entrepreneur. The entrepreneur is both the owner and the manager of the firm. The overall cost of managing a firm depends on the number of jobs managed and on a parameter which is specific to the manager, and which summarizes the agent's "managerial skill" or "entrepreneurship". Agents choose whether to become entrepreneurs or workers by maximizing expected lifetime income. I show that the choice of career is determined by a cut-off managerial ability, with more able managers choosing to set up their own firms and create jobs. Employment is determined by an aggregate matching function which matches the posted jobs with the agents who choose to become workers.

In contrast to Lucas's (1978) model, managerial skill in my model does not influence the firm's total factor productivity. More able managers in my model spend fewer resources on managing their firm but produce the same output for each job that they own as less able managers. This property enables the derivation of a conventional search and matching equilibrium conditional on the numbers of managers and workers. I do not consider the role of capital and savings, although their introduction should not be difficult, given existing results in search theory.

Section 1 describes the theoretical framework and the key assumption about managers and workers. Section 2 derives the decentralized search equilibrium without start-up costs. Section 3 introduces three different kinds of start-up costs and studies their role in the determination of employment. Section 4 presents some preliminary evidence from 17 OECD countries supporting the link between start-up costs and employment.

\section{The economy}

The economy consists of a continuum of infinitely-lived individuals in the unit interval. Each individual can be either a worker or a manager. Managers establish a firm that they own, create jobs and recruit workers. A manager 
can manage many jobs at the same time but a worker can only occupy one job at a time. A firm is a collection of jobs headed by a single manager. ${ }^{4}$

All agents have linear utility functions and capital markets are perfect and characterized by a safe interest rate $r$. Agents decide to become workers or managers by maximizing utility under rational expectations over their horizon. They are identical in all respects except for their managerial ability, or "entrepreneurship." Managerial ability is summarized in a function that gives the cost of managing jobs. The cost of managing $\alpha$ jobs is given by $x g(\alpha)$, with $x \in\left[x_{0}, \infty\right)$ and $g(\alpha)$ increasing and convex. The parameter $x$ is specific to each individual and has known distribution $F(x)$ over the population. Good managers have low $x$, poor managers have a high $x$. Managerial ability influences only the cost of management. It does not influence the productivity of the worker or manager.

When a firm is first created, the manager posts $\alpha$ job vacancies and workers arrive according to the parameters of a matching technology. The number $\alpha$ is chosen optimally to maximize profit, so in general it will depend on $x$. Because a firm is owned and headed by a single manager, we can identify firms with managers and with the parameter $x$. We can therefore refer to firm $x$ or manager $x$. When the firm is mature some of its $\alpha(x)$ jobs will be occupied and some vacant. We refer to the occupied jobs as employment in firm $x$, and denote it by $n(x)$. Posted vacancies in firm $x$ are then given by $\alpha(x)-n(x) \geq 0$. The cost of managing a job is the same irrespective of whether it is vacant or filled, an assumption that can easily be relaxed.

Each occupied job produces a constant flow of output $y$ and continues producing this output until the worker leaves. In the simple version of the model in this paper I assume that there are no productivity shocks and the only reason for the interruption of production is an exogenous process that separates workers from jobs. The separation process could be interpreted as exogenous death and replacement of the worker or manager, with only trivial modifications to the argument. I simplify the exposition by assuming that there is no death and replacement, all agents have infinite horizons but they are separated at constant Poisson rate $\lambda$. After separation the job is re-advertised as a vacancy and the worker becomes unemployed to search

\footnotetext{
${ }^{4}$ Although I do not refer explicitly to self employment, the model can easily be extended to deal with it. For example, a self employed individual can be interpreted as a firm that yields some output with no workers besides the manager. I simplify the exposition by assuming that although managers are never unemployed, the firm cannot yield output without workers.
} 
for another job. Unemployed workers enjoy income flow $b$ but job vacancies produce and cost nothing (with the exception of their management cost).

The allocation of jobs to workers is modelled as in the simplest case analyzed in Pissarides (2000, chapter 1), with an important modification necessitated by the introduction of managers. Suppose at some time $t$ entrepreneurs have created and are managing a total of $n+v$ jobs, with $n$ of them occupied by workers and $v$ of them vacant. There are $n+u$ workers in this market, one in each occupied job and $u$ unemployed. The $v$ vacant jobs and $u$ unemployed workers engage in a process of search and matching governed by an aggregate matching function with constant returns to scale. It is shown in Pissarides (2000, chapter 1) that under these assumptions the arrival process can be summarized by a single parameter, the tightness of the market $\theta \equiv v / u$, such that: workers arrive to jobs according to a Poisson rate $q(\theta)$, which has elasticity in the interval $(-1,0)$, and jobs arrive to unemployed workers according to a related Poisson rate $\theta q(\theta)$, with elasticity in the interval $(0,1)$ and with

$$
\begin{aligned}
\lim _{\theta \rightarrow \infty} q(\theta) & =\lim _{\theta \rightarrow 0} \theta q(\theta)=0 \\
\lim _{\theta \rightarrow 0} q(\theta) & =\lim _{\theta \rightarrow \infty} \theta q(\theta)=\infty
\end{aligned}
$$

\section{Decentralized search equilibrium}

There are several ways in which a decentralized search equilibrium can be specified and solved. The key properties of a search equilibrium, which were noted by Phelps in his two seminal contributions in search theory (Phelps et al., 1970, Phelps 1972), are first, that search frictions introduce monopoly rents, and second, in the decentralized solution the dependence of the aggregate arrival rates on individual actions are ignored. The first implies that we need a monopoly solution to wage determination and the second that there are congestion externalities that are likely to be ignored in the individual optimization problems. In this paper I will study the decentralized equilibrium when wages split the monopoly rents from each job between the worker and the manager according to the arbitrary constant $\beta \in(0,1)$, with $\beta$ denoting the share of the worker in each job. This solution to wage determination is different from the "wage posting" solution adopted by Phelps in his seminal contributions (and more recently by Burdett and Mortensen (1998), among others). It can be derived from the solution to the static Nash bargain, when 
the bargain takes place between isolated pairs of managers and workers, but I will not explore its foundations here and treat $\beta$ as an arbitrary constant.

\subsection{Managers and workers}

If an individual decides to become a worker, she can search for a job offered by a manager. If she becomes an entrepreneur, she can create $\alpha$ jobs and post vacancies waiting for workers to arrive. Individuals decide whether to become managers or workers by maximizing income over an infinite horizon, with constant discount rate $r$.

Let $U$ be the present discounted value of income of the searching worker and $V$ the expected PDV of profit income from a vacant job. Both $U$ and $V$ are independent of the individual's managerial ability $x$. The cost of managing $\alpha$ jobs is $x g(\alpha)$, irrespective of whether they are occupied or vacant. Therefore, with infinite horizon, in the steady state the total management cost paid by an $x$ individual who creates $\alpha$ jobs is $x g(\alpha) / r$. By creating one more job a manager can enjoy additional income over the infinite horizon of $V$, for an additional lifetime management cost of $x g^{\prime}(\alpha) / r$. Therefore, the optimal $\alpha$ satisfies

$$
x g^{\prime}(\alpha(x))=r V .
$$

The marginal cost of managing a job is equal to the "permanent income" generated by a new job vacancy, the marginal revenue from the posting of one more job vacancy. It is constant across firms, because $V$ is independent of the manager's ability. This immediately gives the distribution of jobs across managers in terms of the marginal costs of management and the distribution of abilities. If two managers have ability $x$ and $x^{\prime}$ respectively, and create $\alpha$ and $\alpha^{\prime}$ jobs respectively, they satisfy, $x g^{\prime}(\alpha)=x^{\prime} g^{\prime}\left(\alpha^{\prime}\right)$. For example, if $g(\alpha)=\gamma \alpha^{2} / 2, \alpha^{\prime}=\alpha x / x^{\prime}$.

If an $x$ individual becomes an entrepreneur and creates $\alpha(x)$ jobs, her initial net expected payoff is $\alpha(x) V-x g(\alpha(x)) / r$. If she becomes a worker, her initial payoff is $U$. Therefore, individuals whose $x$ satisfies the following inequality become entrepreneurs:

$$
\max _{\alpha}\{\alpha V-x g(\alpha) / r\} \geq U
$$

As expected, the maximization condition is (3). Agents who become entrepreneurs will post the maximum number of jobs immediately. 
Individuals who have been entrepreneurs for a while will have some jobs filled and some vacant. Because of the obvious property that filled jobs do not have lower expected payoffs than vacant jobs, no agent who satisfies inequality (4) will drop out of entrepreneurship and become a worker after some jobs are filled. Similarly, individuals who do not satisfy (4), and are therefore workers, will eventually find a job. Because the expected returns from employment are at least as high as the expected returns from unemployment, if (4) is not satisfied for an unemployed worker it will not be satisfied for an employed worker. Therefore, (4) is a general condition for the allocation of agents between entrepreneurship and worker status.

$V$ and $U$ are both independent of $x$ by assumption, so (4) satisfies the reservation property: there is a reservation managerial ability $R$, such that an $x$ individual becomes an entrepreneur if $x \leq R$, otherwise she becomes a worker. The reservation ability satisfies

$$
R=\frac{\alpha(R) r V-r U}{g(\alpha(R))}
$$

with $R g^{\prime}(\alpha(R))=r V$. Conditions (4) and (5) state the obvious property that the income flow from the $\alpha$ jobs, $\alpha(x) r V$, has to cover their management cost and the manager's loss of the expected returns from search.

\section{$2.2 \quad$ Expected payoffs}

The expected payoffs to workers and job owners are derived as in conventional search models. The PDV of income of a posted vacancy, $V$, satisfies

$$
r V=q(\theta)(J-V),
$$

where $J$ are the expected returns from an occupied job, which satisfy

$$
r J=y-w-\lambda(J-V) .
$$

The job switches between employment and vacancy according to the transition rates $q(\theta)$ and $\lambda$. When it is vacant it produces and costs nothing but when it is filled it produces $y$, yielding net income $y-w$ to the manager, with $w$ going to the worker. Management costs can be ignored in these calculations because they are the same for both vacancies and filled jobs.

The unemployed worker's PDV of income, $U$, satisfies

$$
r U=b+\theta q(\theta)(W-U)
$$


where $W$ are the expected returns from holding a job, and satisfy

$$
r W=w-\lambda(W-U) .
$$

The worker moves from unemployment to employment and back at rates $\theta q(\theta)$ and $\lambda$ respectively, with income in unemployment given by $b$ and in employment by $w$.

Wages share the surplus from the job match according to the fixed parameter $\beta \in(0,1)$. Total surplus is given by $J-V+W-U$, with $J-V$ going to the owner of the job and $W-U$ going to the worker. Therefore wages solve

$$
(1-\beta)(W-U)=\beta(J-V) .
$$

From (8), (10) and (6), we obtain

$$
r U=b+\frac{\beta \theta}{1-\beta} r V .
$$

Adding up the value equations (6)-(9) and making use of the sharing rule (10) to substitute out $W-U$ and $J-V$ in terms of the surplus from the job, we obtain the following expression for the surplus:

$$
J-V+W-U=\frac{y-b}{(1-\beta) q(\theta)+r+\lambda+\beta \theta q(\theta)} .
$$

(6), (10) and (12) yield

$$
r V=\frac{(1-\beta) q(\theta)(y-b)}{(1-\beta) q(\theta)+r+\lambda+\beta \theta q(\theta)} .
$$

We can therefore write $V=V(\theta)$, with $V^{\prime}(\theta)<0$. This is an important property: intuitively, the larger the number of jobs posted by all firms for each unemployed worker, the less the expected profit of each firm from posting one more vacancy. The reason for this result is the congestion externality caused by the posting of vacancies, because production is not characterized by diminishing returns to the number of jobs. The implications for equilibrium, however, are similar. At the aggregate level, the marginal profit from one more job falls as the number of jobs increases.

Given now (13), (11) implies that $U=U(\theta)$ with $U^{\prime}(\theta)>0$. Workers are made better off when more jobs are posted for each unemployed worker. 
Once again, the reason for this result is the search externality associated with these models.

Note finally that although we cannot say in general whether the PDV of income is higher or lower for a worker or her manager, it follows immediately from the value equations that for as long as $y>b$, a necessary condition for a nontrivial equilibrium, $J \geq V$ and $W \geq U$; i.e. both managers and workers are better off when they are producing than when they are searching. These inequalities confirm that if the career choice condition (4) is satisfied for unemployed agents then it is certainly satisfied for employed ones.

\subsection{Equilibrium}

An equilibrium is defined as a reservation managerial ability $R$, a market tightness $\theta$, and distributions of jobs, employment and wages $(\alpha(x), n(x), w(x))$ across managers, given the distribution of abilities $F(x)$. The equilibrium satisfies the value equations (6)-(9), the wage sharing rule, (10), the career choice rule (4), the marginal job entry rule, (3), and the equation for the evolution of employment in each firm,

$$
\dot{n}(x)=(\alpha(x)-n(x)) \theta q(\theta)-\lambda n(x) .
$$

I illustrate the solution with the help of a diagram.

The results in (11) and (13) imply that the equilibrium $R$, which satisfies (5), is a monotonically decreasing function of aggregate tightness, $\theta$. When tightness is higher, managers find it more difficult to recruit workers, so fewer individuals decide to start their own companies and more become workers. This relationship is shown in $(R, \theta)$ space as a downward-sloping curve labeled "entrepreneurship" (see figure 1). The limits to this curve are derived as follows.

If $\theta=0,(13)$ and (1) and (2) imply $r V=y-b$ and (11) implies $r U=b$. Therefore, from (5) we derive $R g\left(\alpha(R)=\alpha(R)(y-b)-b\right.$, where $R g^{\prime}(\alpha(R))=$ $y-b$. This gives the maximum feasible value of $R$. It also follows from (4) that for any choice of $\alpha(x)$, in a feasible equilibrium $\alpha(x) V(\theta) \geq U(\theta)+x g(\alpha(x))>$ 0 . Define therefore $\tilde{\theta}$ by $V(\tilde{\theta})=0$ and $\theta_{0}$ by $\alpha\left(x_{0}\right) V\left(\theta_{0}\right)=U\left(\theta_{0}\right)+x_{0} g\left(\alpha\left(x_{0}\right)\right)$, where $x_{0}$ is the ability of the best manager. Equilibrium is non-trivial only for values of $\theta$ that satisfy $\theta \leq \theta_{0}<\tilde{\theta}$. $\tilde{\theta}$ is the equilibrium value of tightness in models that derive the demand for labor from a zero-profit condition on the value of a new vacancy (as in Pissarides, 2000; of course, if there are 
management costs in these models, the zero-profit condition would have to take them into account). $\theta_{0}$ is the tightness level at which finding a new worker is so difficult, that only the most able manager in the market will choose to become an employer. See figure 1.

In order to derive a second equilibrium relationship between $\theta$ and $R$, consider the definition of $\theta$ as the ratio of aggregate vacancies to unemployment. With each firm owner creating $\alpha\left(x \mathrm{R}_{R} \mathrm{jobs}\right.$, aggregate vacancies for any aggregate employment level $n$ measure ${ }_{x_{0}} \alpha(x) d F(x)-n$. With all agents with managerial ability at least as good as $R$ becoming managers, unemployment is $1-F(R)-n .1-F(R)$ is the total numbers of workers in the economy and $n$ is their employment level. Hence

$$
\theta=\frac{{ }_{x_{0}}^{\mathrm{R}_{R}} \alpha(x) d F(x)-n}{1-F(R)-n} .
$$

The evolution of aggregate employment is given by aggregating over $x$ in (14). In the steady state employment in each firm satisfies

$$
n(x)=\frac{q(\theta)}{q(\theta)+\lambda} \alpha(x) .
$$

Aggregating over $x$ we obtain one expression for aggregate employment in the steady state:

$$
n=\frac{q(\theta)}{q(\theta)+\lambda}{ }_{x_{0}}^{\mathbf{Z}_{R}} \alpha(x) d F(x) .
$$

A second expression is derived by focusing on worker flows. The flow of unemployed workers into employment is $\theta q(\theta)(1-F(R)-n)$ and the flow of employed workers into unemployment is $\lambda n$. Equating the two flows gives steady state employment

$$
n=\frac{\theta q(\theta)}{\theta q(\theta)+\lambda}(1-F(R))
$$

Substitution from (18) and (17) into (15) yields

$$
\frac{\theta q(\theta)+\theta \lambda}{\theta q(\theta)+\lambda}=\frac{{ }_{x_{0}} \alpha(x) d F(x)}{1-F(R)} .
$$

Now, from (3) and (13) each $\alpha(x)$ is a function of $x$ and $V(\theta)$, with

$$
\frac{\partial \alpha(x)}{\partial \theta}=\frac{\partial \alpha(x)}{\partial V} \frac{\partial V}{\partial \theta}<0 \quad \forall x .
$$


Total differentiation of (19) therefore gives $d \theta / d R>0$ : at higher $R$ there are more managers and fewer workers, so more jobs are created and posted for each job seeker. We refer to this curve in $(R, \theta)$ space as job creation. As $R \rightarrow x_{0}, \theta \rightarrow 0$, giving the shape of the curve shown in figure 1 .

Equilibrium is now straightforward to obtain. The equilibrium $R$ and $\theta$ are unique and shown by the intersection of the two curves in figure 1 . With knowledge of $R$ and $\theta, V$ and $U$ can be obtained from (11) and (13), and (3) then gives $\alpha(x)$ for each firm $x$. With knowledge of $\alpha(x)$, employment in each firm is obtained from (16). To obtain wages, note that the value equation (7) can be rearranged to yield

$$
J-V=\frac{y-w-r V}{r+\lambda}
$$

and the one for $W,(9)$, yields

$$
W-U=\frac{w-r U}{r+\lambda} .
$$

Substitution into the sharing rule (10) gives

$$
w=(1-\beta) r U+\beta(y-r V),
$$

which can be solved for wages. It is noteworthy that wages are common across all jobs and managers: better managers do not pay more, despite the decentralized sharing rule and the frictions that do not eliminate monopoly rents.

\section{The role of start-up costs}

In the equilibrium derived in the preceding section agents could become managers and set up a firm without any fixed costs or waiting time. Evidence, however, points to large start-up costs, partly in the form of legal procedures that have to be satisfied before a business firm can open its doors, partly in terms of a waiting time for the permit to arrive and partly in the form a fee that has to be paid to the authorities. Our framework is ideally suited to the introduction of costs of this kind. Although in the simple version of the model that I described here all costs have similar impact on the equilibrium allocation of agents and job creation, I will consider separately the role of three distinct costs. 
First, an agent who decides to become entrepreneur has to start legal procedures for the creation of her company. Next, a permit giving the licence to start operating comes with some randomness. And finally, when the permit arrives, the entrepreneur has to pay a fee to the authorities to receive the registration documents. I assume that permits arrive stochastically, at rate $a>0$. The expected waiting time for a new company is $1 / a$. This rate is influenced mainly by policy, although in many countries it is possible to speed up the procedure by paying "bribes" (see Djankov et al., 2000). During the waiting time, the entrepreneur has to give up her worker status and pay some out-of-pocket costs to go through the necessary procedures. I represent these costs as a flow $c \geq 0$, paid until the permit arrives. When the permit arrives, a fee $s \geq 0$ is paid and the company starts operation.

A new company headed by an individual of ability $x$ starts operations with $\alpha(x)$ posted vacancies, which satisfy the marginal condition (3). The value of the firm at start-up is $\alpha(x) V(\theta)-x g(\alpha(x))$, which I denote for simplicity by $S(x, \theta), S_{x}, S_{\theta}<0$. The introduction of the start-up costs does not alter this value for given $\theta$ and $x$, so its solution is known from the preceding analysis.

Let the entrepreneur's optimal PDV of income when the decision is made to apply for a new company be $Q$. With discount rate $r$ and the stationary policy variables $a, c, s$, this value satisfies the Bellman equation

$$
r Q=-c+a(S(x, \theta)-s-Q) .
$$

The entrepreneur pays $c$ per period until a permit arrives, which changes her state from $Q$ to $S$, for a fee $s$. Solving (24) for $Q$ gives

$$
Q(a, c, s, \theta ; x)=\frac{a}{r+a} S(x, \theta)-\frac{c+a s}{r+a} .
$$

Given knowledge of $S(x, \theta), Q()$ is immediately obtained from (25) because $r, a, c$ and $s$ are all parameters.

Equation (25) implies that for given $x$ and $\theta$, the value of applying for a new firm falls in the $\operatorname{costs} c$ and $s$ and rises in the arrival rate of the permit $a$ (and so falls in the expected waiting time 1/a). An $x$ individual will apply for a new company if $Q(a, c, s, \theta ; x) \geq U(\theta)$. Because $Q()$ falls monotonically in $x$, a reservation rule similar to the one in (5) is again satisfied. At the optimal $R$,

$$
\frac{a}{r+a} S(R, \theta)-\frac{c+a s}{r+a}=U(\theta) .
$$


Equation (26) can be represented in $(R, \theta)$ space as a downward-sloping curve similar to the entrepreneurship curve of figure 1, but now shifts down in the $\operatorname{costs} c$ and $s$ and in the expected delay 1/a. The start-up costs do not influence any of the other expressions in the derivation of equilibrium, because workers arrive and wage determination takes place after the company is set up and the costs paid.

The influence of start-up costs can be derived with the help of figure 2 . They shift the entrepreneurship curve down and so reduce the fraction of the population who become entrepreneurs. Employment falls for two reasons. First, because entrepreneurs have higher employment rates than workers, the shift from managers to workers reduces employment. We refer to this as the composition effect of start-up costs. Overall employment is given by the sum of the number of managers and the aggregate employment of workers:

$$
F(R)+n=\frac{\lambda F(R)+\theta q(\theta)}{\lambda+\theta q(\theta)}
$$

The composition effect is shown by a lower $F(R)$.

Second, with fewer entrepreneurs, job creation is lower, so fewer workers find jobs. We refer to this as the job creation effect of start-up costs. It is shown in (27) by a lower $\theta q(\theta)$.

Start-up costs reduce market tightness and so through (13) increase the expected profit from a new vacancy. This is an equilibrium response to the costs: new entrepreneurs have to pay the start-up costs and so need higher expected profit from new jobs to compensate them. The costs are borne by workers in the form of higher unemployment, lower wages and lower PDV of income of both employed and unemployed persons, implied by (11) and (23).

The number of jobs in each existing firm, however, increases, because of the increase in the expected profit per job, as implied by (3) and (20). Start-up costs protect the incumbents, who now make more profit per job and create more jobs. But the market as a whole suffers, because the number of entrepreneurs now falls and there is less aggregate job creation. This is what Djankov et al. (2000) call the "grabbing-hand" view of regulation. Following Stigler's analysis of regulation, they argue that one of the reasons for regulation is to make entry more difficult and create rents for incumbents. Their second version of the "grabbing-hand", what they call the "tollbooth view" of entry costs, is also satisfied by the model. This is that the reason for start-up costs is for the politicians to collect revenue, which is represented in 
the model by the two cost variables $c$ and $s .^{5}$

Our model can also be used to analyze the impact of bribes. It is asserted by many (see again Djankov et al.) that entrepreneurs can pay bribes to speed up the arrival of permits for business start ups. Let the bribe be a payment $p$, made when the permit arrives (the analysis is similar if it is paid during the waiting period with no guarantee of a faster arrival). The bribe speeds up arrival by increasing the arrival rate $a: a=a(p), a^{\prime}(p)>0$. Then (24) changes to

$$
r Q=\max _{p}\{-c+a(p)(S(x, \theta)-s-p-Q)\}
$$

The optimal bribe increases in the expected payoff $S(x, \theta)$ and the recurring cost $c$ but decreases in the fee $s$ under standard restrictions.

\section{Some preliminary evidence}

Several factors related to policy have been identified as contributing to country differences in employment or unemployment rates. The problem that has to be confronted when considering the influence of company start-up costs is how to distinguish the influence of start-up costs from the influence of other related variables, given that a country that has a lot of regulation in company start-ups is also likely to have a lot of regulation elsewhere. My modest objective in this section is to look at some partial correlations between start-up costs and employment performance and at the relation between start-up costs and another much-researched regulation candidate, employment protection legislation.

In Table 1 I report two sources of data for start-up costs for major countries of the OECD. The first two columns report data gathered by Logotech and reported by Fonseca et al. (2001). Column (1) gives the number of procedures needed to register a company. A procedure is anything that has to be done in an office outside the company's premises, such as filling-in a form and submitting it for obtaining a VAT number. Column (2) gives the average number of weeks that lapse between the first application for a start-up and the first legal trading day. Column 3 combines these series into a single

\footnotetext{
${ }^{5}$ Their first, Pigovian view, that regulation gives consumers a "helping hand" by ensuring that only good entrepreneurs start up is not in the model. They do not find evidence for it.
} 
index. In order to compile the index, we first calculate how many procedures are on average completed within a week in the sample as a whole. We then divide the actual number of procedures that a country requires by the average and obtain a series that has the dimension of weeks, but which is a linear transformation of the number of procedures. Our index is the average of the actual number of weeks needed and the constructed series.

Columns 4-6 report data compiled by Djankov et al. (2000). Again, the first two columns report the number of procedures and the expected waiting time, in business days. Column 6 gives the expected cost as a percent of GDP per capita in 1997.

Although there are differences between the two data sources, the correlations is high. Table 2 reports correlation coefficients. The correlation between the two series for procedures is 0.64 , which is almost identical to the correlation between the two series for waiting times (not reported in the Table). The Table also reports the correlations between the start-up series and the OECD's index for employment protection legislation, which is representative of labor-market regulation. The correlation is positive and over 0.70 with all measures of start-up costs, indicating that countries with a lot of regulation of company start-ups also have a lot of labor regulation.

The correlations between employment-to-population ratios and the measures for start-up costs are better than the respective correlations with unemployment. The series compiled by Fonseca et al. (2001) give better correlations, which are in turn better than the correlations between employment and employment protection. Figure 3 shows the correlation between the index for start-up costs and the employment-to-population ratio (which is about the same as the one with the number of procedures). The correlation is better than the one between employment and employment protection, shown in figure 4 (0.80 versus 0.60). Figures 5 and 6 show the partial correlations between unemployment and the respective measures of regulation. Again, although the fit is not as good as for employment, it is better with our index of start-up costs than with employment protection legislation.

Despite the correlation between start-up costs and employment protection, the partial correlations give encouraging results about the likely importance of start-up costs in the explanation of OECD employment. ${ }^{6}$

\footnotetext{
${ }^{6}$ With only 17 observations not much more can be said at this stage. However, a simple regression of employment rates on the start-up index (or the number of procedures) and employment protection gives a significant result for start-up costs (t-statistic -3.25) but not for EPL (t-statistic -0.02), with an $\mathrm{R}^{2}$ of 0.64 . If the dependent variable is unemployment,
} 


\section{Conclusions}

The motivation for this paper is very much that in Edmund Phelps' book Structural Slumps: the factors that can explain the differences in labor market performance across the OECD are "structural," and should be sought in the institutional structures of the countries. The factor discussed in this paper is one neglected by previous studies, the regulatory framework for the establishment of new companies. I have shown how the costs that governments impose on new entrepreneurs can give rise to differences in equilibrium employment rates, within a fairly standard model of equilibrium search with career choice. A preliminary examination of the data shows that there are large differences across the OECD in company start-up costs and that these costs are strongly correlated with employment performance. Of course, although lower costs of entering an activity in the labor market are obviously better than higher costs, this paper has nothing to say about the welfare aspects of regulation in business start-ups. Regulation is exogenous in the model and its implications for the labor market are the trivial ones of imposing some entry costs on new entrepreneurs. My purpose was to examine the extent to which the different entry costs imposed by governments across essentially similar economies have implications for the observed differences in labor market performance. Fewer costs are not necessarily better than more costs along all their dimensions.

The next step in this research is a more general model of employment determination that can distinguish between the regulation of entry and other types of regulations. I have made a beginning in this paper by looking at labor regulation, in the form of employment protection legislation. Although the correlation between start-up costs and employment protection measures is positive and high, start-up costs appear to be better correlated with employment performance than is employment protection. The welfare aspects of different aspects of regulation and start-up costs also need to be examined before policy recommendations can be made.

the t-statistic on start-up costs is 2.75 and on employment protection -0.46 , with $\mathrm{R}^{2}=0.49$. It is intended to test formally the propositions of this paper in future work. 


\section{References}

[1] Blanchard, O. J. (1999). "European Unemployment: The Role of Shocks and Institutions." Baffi Lecture, Rome.

[2] Blanchard, O. J. and J. Wolfers (2000). "The Role of Shocks and Institutions in the Rise of European Unemployment: the Aggregate Evidence." Economic J ournal 110, C1-C33.

[3] Bruno, M. and J. D. Sachs (1985). E conomics of W orldwide Stagflation. Cambridge, Massachusetts: Harvard University Press.

[4] Burdett, K. and D. T. Mortensen (1998). "Wage Differentials, Employer Size, and Unemployment." International E conomic Review 39, 257-273.

[5] Djankov, S., R. La Porta, F. Lopez-de-Silanes and A. Shleifer (2000). "The Regulation of Entry." Discussion Paper No. 1904, Harvard Institute of Economic Research.

[6] Fonseca, R., P. Lopez-Garcia and C. A. Pissarides (2001). "Entrepreneurship, Start-up Costs and Employment." E uropean E conomic Review 45, 692-705.

[7] Layard, R., S. Nickell and R. Jackman (1991). Unemployment: Macroeconomic Performance of the Labour Market. Oxford: Oxford University Press.

[8] Lucas, R. E. (1978). "On the Size Distribution of Business Firms." Bell J ournal of E conomics $9,508-523$.

[9] Phelps, E. S. (1972). Inflation Policy and Unemployment Theory: The Cost-Benefit Approach to Monetary Planning. New York: Norton.

[10] Phelps, E. S. (1994). Structural Slumps. Cambridge, MA: Harvard University Press.

[11] Phelps, E. S. et al. (1970). Microeconomic Foundations of Employment and Inflation Theory. New York: Norton.

[12] Pissarides, C. A. (2000). Equilibrium Unemployment Theory. 2nd ed., Cambridge, MA: MIT Press. 
Table 1

Company Start-Up Costs, 1997-8

\begin{tabular}{l|cccccc} 
Country & $\begin{array}{c}\text { Procedures } \\
(\mathbf{1})\end{array}$ & $\begin{array}{c}\text { Weeks } \\
\mathbf{( 2 )}\end{array}$ & $\begin{array}{c}\text { Index } \\
\mathbf{( 3 )}\end{array}$ & $\begin{array}{c}\text { Procedures } \\
\mathbf{( 4 )}\end{array}$ & $\begin{array}{c}\text { Days } \\
\mathbf{( 5 )}\end{array}$ & $\begin{array}{c}\text { Cost } \\
(\mathbf{6})\end{array}$ \\
\hline Australia & 6.5 & 1 & 2.47 & 3 & 3 & 0.021 \\
Austria & 10 & 8 & 7.03 & 12 & 154 & 0.454 \\
Belgium & 7 & 6 & 5.12 & 8 & 42 & 0.010 \\
Denmark & 2 & 1 & 1.11 & 5 & 21 & 0.014 \\
Finland & 7 & 6 & 5.12 & 4 & 32 & 0.012 \\
France & 16 & 6 & 7.85 & 16 & 66 & 0.197 \\
Germany & 10 & 16 & 11.03 & 7 & 90 & 0.085 \\
Greece & 28 & 6.5 & 11.73 & 13 & 53 & 0.480 \\
Ireland & 15 & 3 & 6.04 & 4 & 25 & 0.114 \\
Italy & 25 & 10 & 12.57 & 11 & 121 & 0.247 \\
Japan & 14 & 3 & 5.74 & 11 & 50 & 0.114 \\
Luxembourg & 5 & 2 & 2.51 & & & \\
Netherlands & 9 & 12 & 8.73 & 8 & 68 & 0.190 \\
Portugal & 10 & 8 & 7.03 & 12 & 99 & 0.313 \\
Spain & 17 & 23.5 & 16.90 & 11 & 83 & 0.127 \\
Sweden & 7 & 3 & 3.62 & 4 & 17 & 0.025 \\
United Kingdom & 4 & 1 & 1.71 & 7 & 11 & 0.006 \\
United States & 3.5 & 1.5 & 1.81 & 4 & 7 & 0.010 \\
& & & & & &
\end{tabular}

Notes: Columns (1) and (4) give the number of procedures that a new company has to go through before starting operations. Column (1) is from Fonseca et al (2001) and column (4) from Djankov et al (2000). Columns (2) and (5) give the average length of time, in weeks and business days respectively, needed to complete these procedures. Sources as above. Column (3) combines the first two measures according to the formula (no. of weeks + no. of procedures/average procedures per week)/2. The average is computed as the ratio of the sum of procedures to the sum of weeks, so the index has the sample mean of weeks. Column (6) gives the expected financial cost as a percent of GDP per capita in 1997. Source, Djankov et al (2000). 
Table 2

Correlations

\section{Employment Unemployment Procedures1 Procedures2 Index}

\begin{tabular}{l|lllll} 
Unemployment & -0.82 & & & & \\
Procedures1 & -0.81 & 0.56 & & & \\
Procedures2 & -0.49 & 0.28 & 0.64 & & \\
Index & -0.80 & 0.70 & 0.77 & 0.59 & \\
EPL & -0.60 & 0.47 & 0.70 & 0.76 & 0.75
\end{tabular}

Notes: Employment is defined as the ratio of employment to population of working age in 1998, Unemployment is the standardized unemployment rate in 1998, Procedures1 is the series shown in column (1) of Table 1, Procedures2 is shown in column (4) of Table 1, Index is the index of start-up costs shown in column (6) of Table 1 and EPL is the OECD's index of employment protection legislation in the late 1990s. 


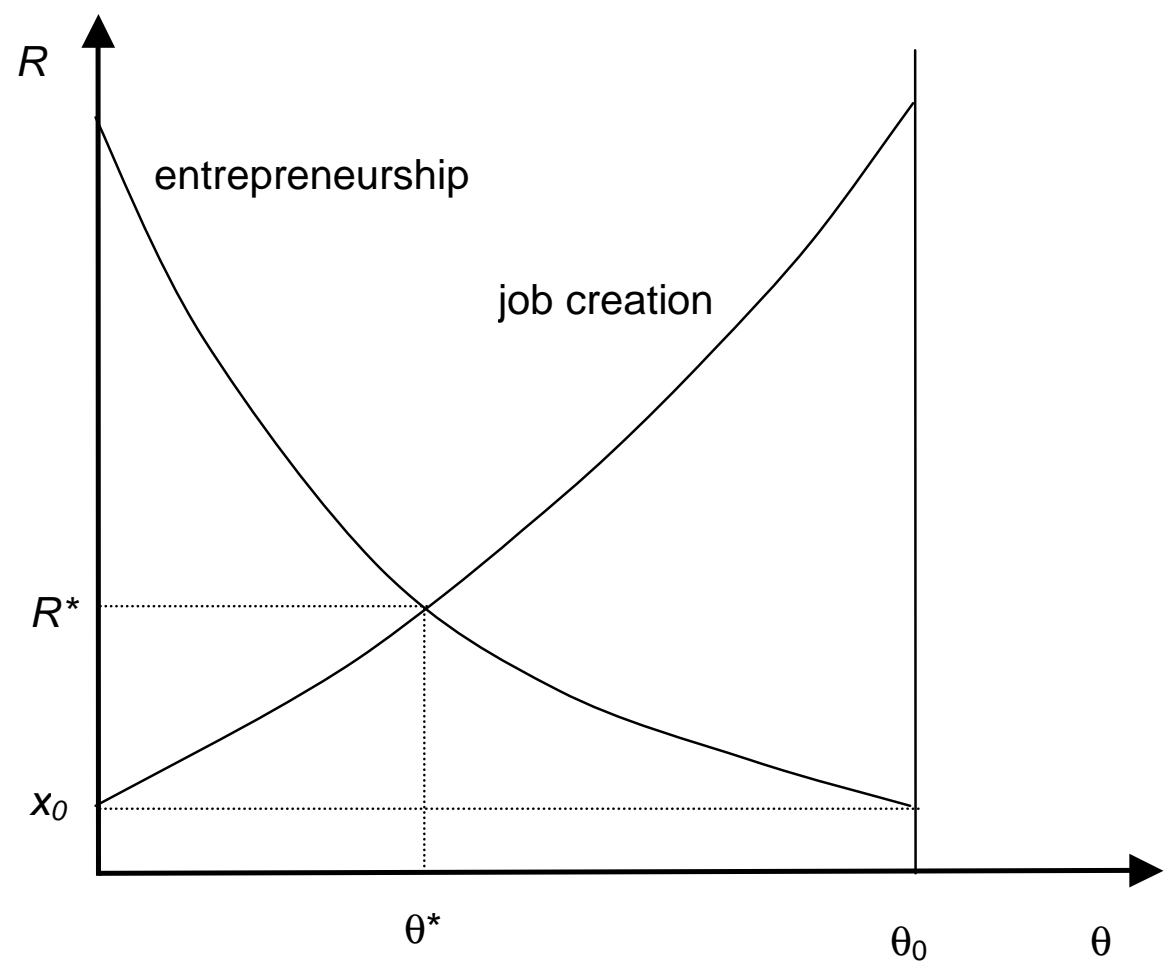

Figure 1

Equilibrium entrepreneurship and labour-market tightness

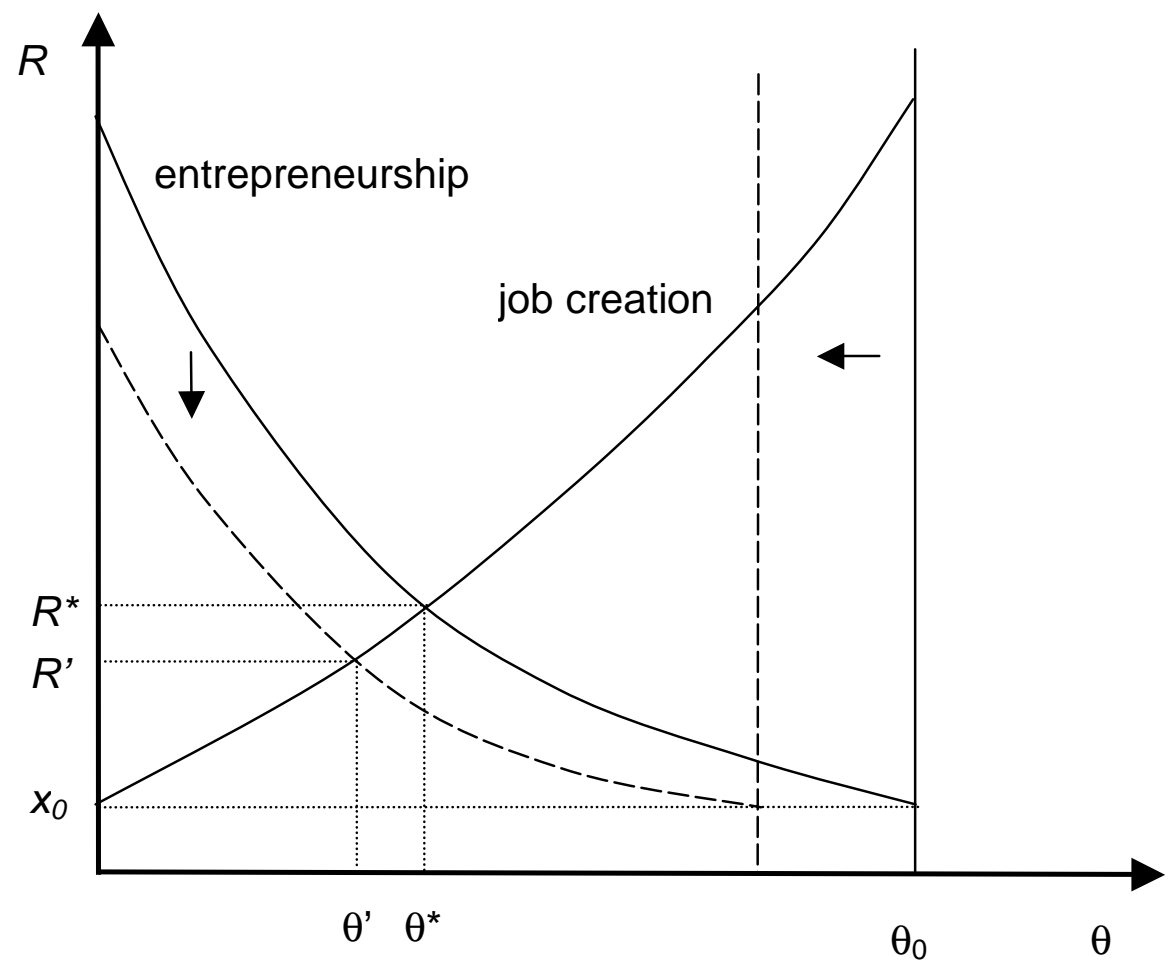

Figure 2

The effect of start-up costs on entrepreneurship and job creation 


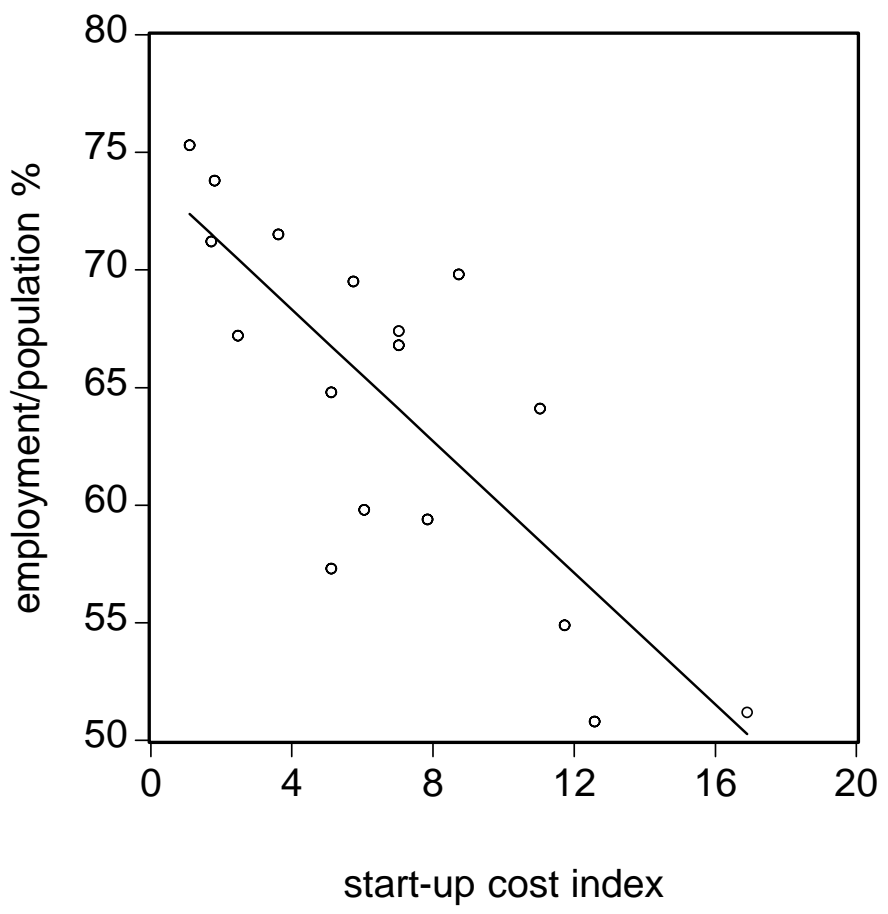

Figure 3

Start-up costs and employment, OECD, 1998

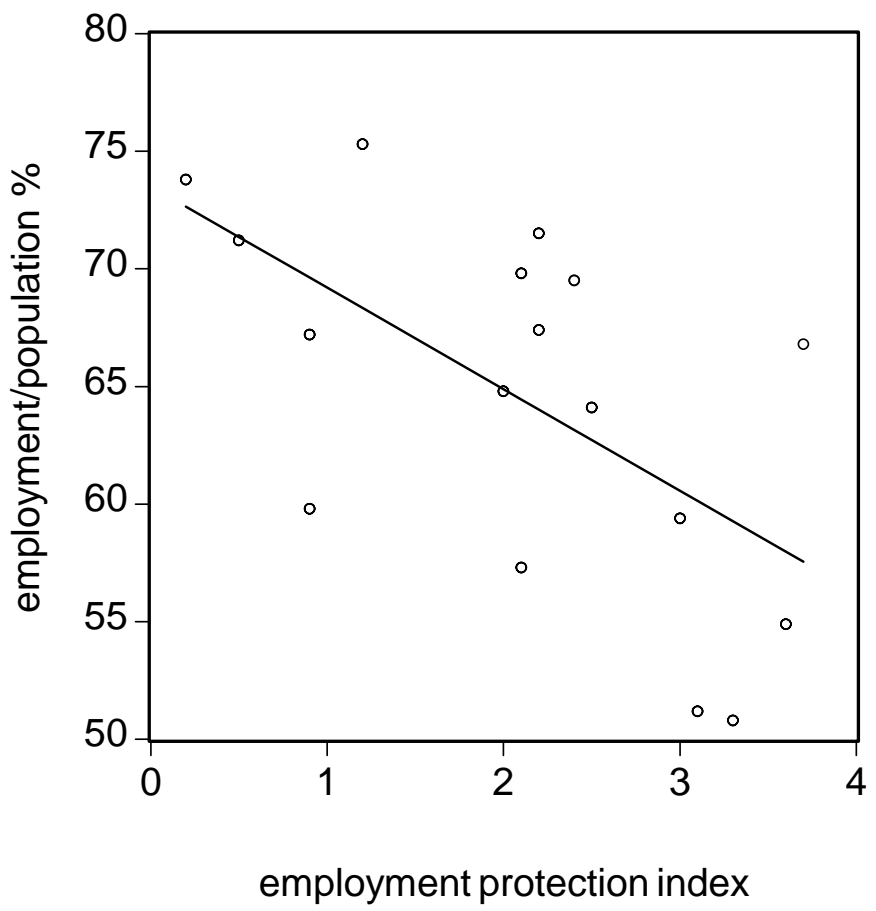

Figure 4

Employment protection legislation and employment, OECD, 1998 


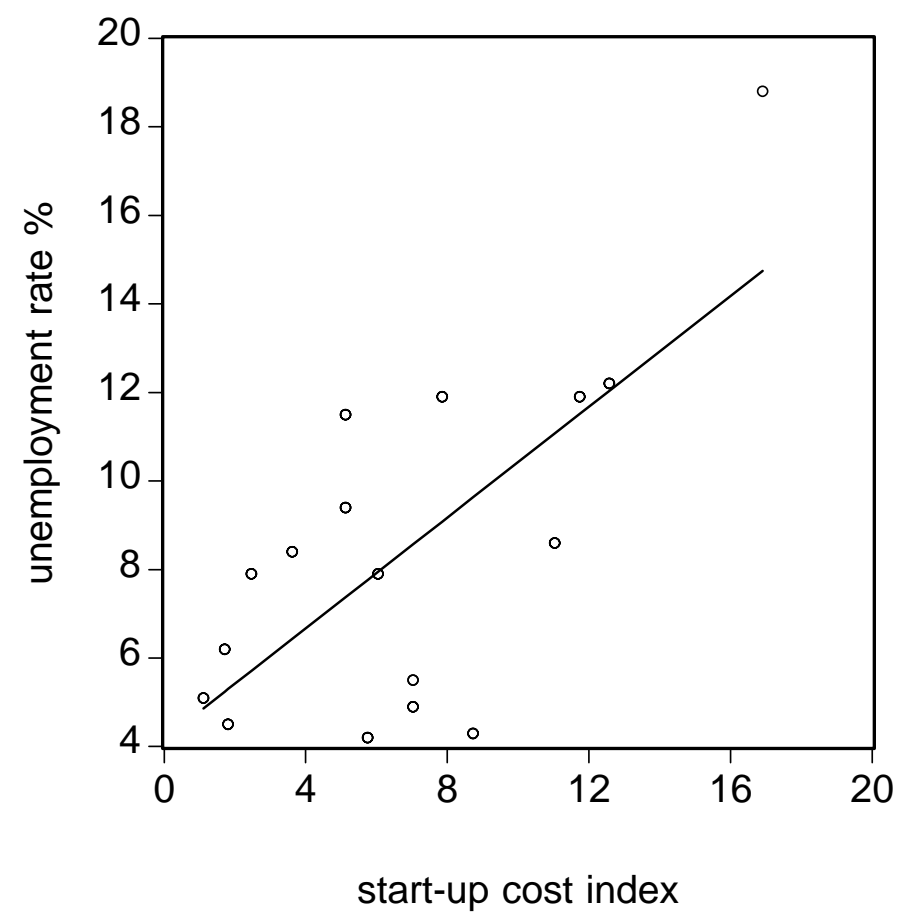

Figure 5

Start-up cost and unemployment, OECD, 1998

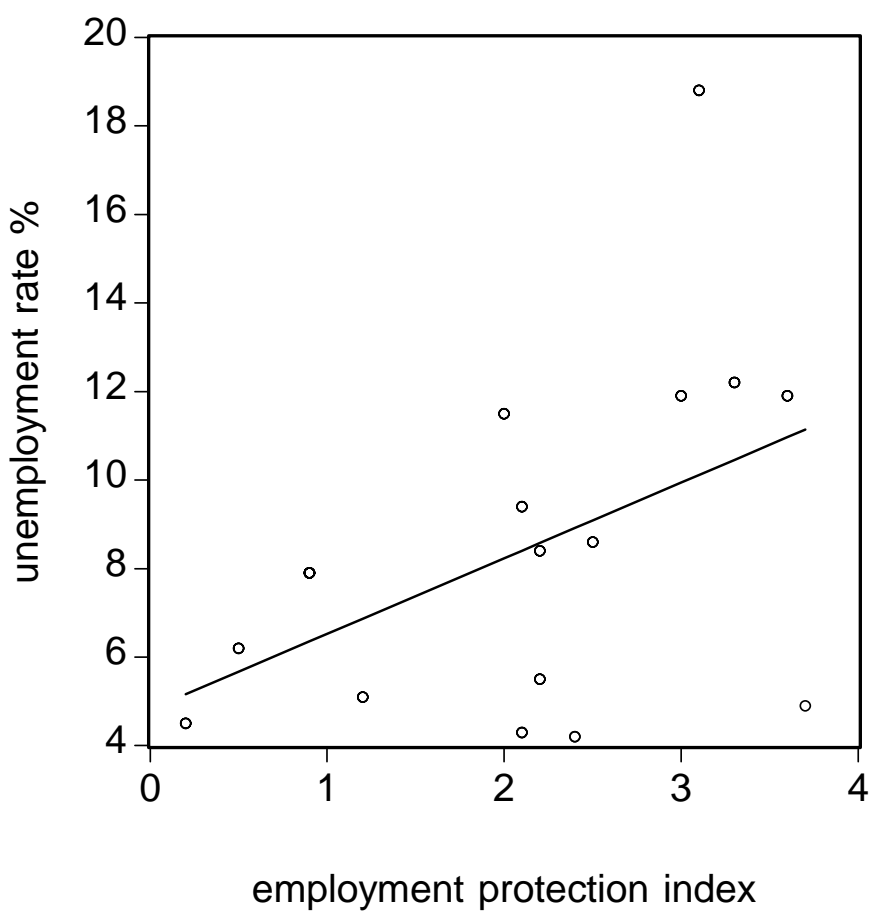

Figure 6

Unemployment and employment protection legislation, OECD, 1998 


\section{CENTRE FOR ECONOMIC PERFORMANCE \\ Recent Discussion Papers}

519 D. T. Mortensen

C. A. Pissarides

518 D. Clark

R. Fahr

517 J. Blanden

A. Goodman

P. Gregg

S. Machin

516 A. Chevalier

T. K. Viitanen

515 A. Bryson

R. Gomez

M. Gunderson

N. Meltz

514 A. Manning

513 H. Steedman

512 R. Gomez

M. Gunderson

N. Meltz

511 G. Duranton

D. Puga

510 P.-P. Combes

G. Duranton

509 R. Griffith

S. Redding

J. Van Reenen

508 H. G. Overman

S. Redding

A. J. Venables
Taxes, Subsidies and Equilibrium Labor Market Outcomes

The Promise of Workplace Training for Non-College

Bound Youth: Theory and Evidence from Germany

Change in Intergenerational Mobility in Britain

The Long-Run Labour Market Consequences of Teenage Motherhood in Britain

Youth Adult Differences in the Demand for Unionisation: Are American, British and Canadian Workers That Different?

Monopsony and the Efficiency of Labor Market Interventions

Benchmarking Apprenticeship: UK and Continental Europe Compared

From 'Playstations' to 'Workstations': Youth Preferences for Unionisation

From Sectoral to Functional Urban Specialisation

Labor Pooling, Labour Poaching, and Spatial Clustering

Measuring the Cost Effectiveness of an R\&D Tax Credit for the UK

The Economic Geography of Trade, Production and Income: A Survey of Empirics

Geography and International Inequalities: the Impact of New Technologies 
Fixed-Term Contracts and the Duration Distribution of Unemployment

504 A. Charlwood

503 D. Marsden

S. French

K. Kubo

502 S. Nickell

L. Nunziata

W. Ochel

G. Quintini

$501 \quad$ S. Redding

M. Vera-Martin

$500 \quad$ Edited by

D. Marsden and

H. Stephenson

499

498 A. Charlwood

497
M. Keil
D. Robertson
J. Symons

496 A. Di Liberto

J. Symons

$495 \quad$ S. Redding

A. J. Venables

494 A. Bryson
Influences on Trade Union Organising Effectiveness in Great Britain

Does Performance Pay De-Motivate, and Does It Matter?

The Beveridge Curve, Unemployment and Wages in the

OECD from the 1960s to the 1990s

Factor Endowments and Production in European Regions

Labour Law and Social Insurance in the New Economy: A

Debate on the Supiot Report

A Generalised Model of Monopsony

Why Do Non-Union Employees Want to Unionise?

Evidence from Britain

Minimum Wages and Employment

Education and Italian Regional Development

Economic Geography and International Inequality

Union Effects on Managerial and Employee Perceptions of Employee Relations in Britain

To order a discussion paper, please contact the Publications Unit Tel 02079557673 Fax 02079557595 Email info@cep.lse.ac.uk Web site http://cep.lse.ac.uk 